\title{
What Do Publishers Know?
}

\author{
Casey Brienza
}

\author{
Department of Culture \& Creative Industries, City University London, Northampton \\ Square, London, EC1V OHB, United Kingdom, casey.brienza.1.city.ac.uk
}

\begin{abstract}
In this short contribution to the open access debate, I will draw upon my expertise as a sociologist who has studied the publishing industry to argue that publishers do in fact have knowledge that is absolutely critical to an informed understanding of open access and how it may be successfully implemented. After providing an overview of who publishers are and what motivates them, along with some of often little-understood complexities of the academic publishing industry, I focus upon the one important thing that publishers understand very well-and far better than most academics-how publishing is funded. I then discuss why collaboration, not competition, between publishers and academics is the only real way forward and conclude with a warning to fellow academics that casually dismissing their potential contribution is both counterproductive and, in the worst case scenario, may threaten the future flourishing of our profession.
\end{abstract}

Keywords: Markets, Funding, Publishing, Open Access

Acknowledgement: For my students and colleagues. Sincerest thanks to Daniel Allington, Anne Barron, and David Mainwaring for valuing the contributions I have made to the open access debate in the past and encouraging me to stay engaged with it in the future.

\section{Introduction}

Although writing journal articles and books is an important, even indispensable, aspect of successful scholarly careers in the twenty-first century, precious few academics know anything at all about the publishing industry that supports this output. For most of us, it would seem, ignorance really is bliss. Nevertheless, there are occasional exceptions, and there are times when the expertise of those rare exceptions is sought. As a cultural sociologist who has studied American manga publishing as a case of transnational cultural production (of all things!), and more recently as Lecturer in Publishing and Digital Media at City University London, I am one of those rare exceptions. I have therefore found myself in the most unexpected of awkward, liminal positions: called upon to explain academic publishing to my university colleagues.

Such inquiries used to be purely instrumental, new acquaintances chatting me up over conference reception drinks and hors d'oeuvres on how to get their first book contract, for example, hoping against hope to glean some insider knowledge that might give them an edge over the competition in the publishing game. "How do I get published?" they would ask, irrational insecurities barely concealed. In the past couple of years, however, both the content and the tenor of the questions have changed. Now, when colleagues want to talk to me about academic publishing, it's hardly ever regarding anxiety-fuelled "how-to" inquiries about monograph proposals anymore. They want to talk instead about the open access movement in academic publishing, and more times than I can remember they have asked, sometimes explicitly, sometimes by unspoken implication, "What do publishers know?"

This question has been posed to me in two senses. The first is a straightforward request for information: Have they done any research to determine what model of open access is most popular or most viable? Do they have privileged information about the latest open access policy proposals being mooted by some government that have not yet filtered down to our level? Are they even listening to us? These colleagues hope to learn from publishers' successes and failures in the implementation of open access publishing policies and initia- 
tives. Increasingly, however, the question is couched differently, not even as a question, really, but rather as a judgment born of contempt. What do publishers know that we do not? They're just self-serving, capitalist parasites taking our work and selling it back to us at grossly inflated prices. Hell, they don't even do a particularly good job of it! Publishers are idiots; there's no reason we academics can't do everything they can do better than they can.

To my dismay, when I am approached with second sense of the question, it is entirely divorced from the first. Some academics would presume to know better before they have ever bothered to learn what it is that publishers actually know! In this short contribution to the open access debate, I will argue that publishers do in fact have knowledge that is absolutely critical to an informed understanding of open access and how it may be successfully implemented. After providing an overview of who publishers are and what motivates them, along with some of often little-understood complexities of the academic publishing industry, I focus upon the one important thing that publishers understand very well - and far better than most academics - how publishing is funded. I then discuss why collaboration, not competition, between publishers and academics is the only real way forward and conclude with a warning to fellow academics that casually dismissing their potential contribution is both counterproductive and, in the worst case scenario, may threaten the future flourishing of our profession.

\section{Who Do They Think They Are?!}

It never ceases to amaze me how little interest in, let alone genuine sympathy for, the lives of academic publishing professionals most scholars have. Indeed, in light of the hostility directed at publishers during the so-called "academic spring" in 2012 and subsequently, I have come to the conclusion that academics resist so vociferously because acknowledging the existence of the publishers compels us to acknowledge that we are not autonomous subjects in the system of scholarly knowledge production and draws attention to our own dominated status in the academic labour system. In this context, we would rather prefer they did not exist at all, and so we often pretend that they don't. It is thus especially important, in my view, to give some attention to who, precisely, publishers are - and more critical still for the purposes of this essay - who they think they are.

Let's start with the obvious. Inasmuch as one can ever make gross generalizations about any large and diverse group of human beings, it would be safe to assert that academic publishers as a group are not money-hungry, capitalist monsters out to strip mine scholarly production of every last possible cent of economic value. It's a well-worn cliché in the publishing industry, but it's also very true - no one goes into publishing for the money. One could expect to hope for a modest, dignified living at best. A former colleague of mine at City University London, who founded his own indie trade press five years ago, is utterly typical in his sentiments: "I never got into publishing for money, and I certainly did not start my own publishing house with thoughts of getting rich quick" (Nayyar 2013). My informal survey of twenty-three Publishing Studies MA students on the first day of class this term on why they were interested in publishing received responses ranging from a love of books and the world of ideas, to a personal commitment to creative and artistic expression, to a keen interest in new digital models of knowledge dissemination and distribution. Not a single student breathed a word about raking in the cash or investing toward an early retirement.

In fact, I would argue, publishing workers and scholars have quite a lot in common. Besides sharing the same sorts of professional motivations which privilege vocational integrity over pure profit seeking, both are highly educated and employed - or precariously employed - in a highly competitive and perennially underfunded field. Many commissioning editors for academic presses themselves have PhDs or other post-baccalaureate degrees. Indeed, some of my closest colleagues and mentors are both university professors and editors for book publishers and/or scholarly journals and are remunerated in both roles. A handful of scholars have even founded their own publishing houses; arguably the most highly regarded of these in sociology is Polity Press, founded and privately owned by Anthony Giddens, David Held, and John Thompson (though currently Thompson is in charge, all three of these men have, historically, been involved in the day-to-day running of Polity). 
Now, to be absolutely clear, I am emphatically not denying that the profits of multinational corporations such as Thomson Reuters and Elsevier or the seeming ruthlessness with which some companies exploit new opportunities in their own and adjacent fields can be problematic. What I would emphasize, however, is that it is exceedingly difficult to issue blanket statements about the whole of academic publishing today, and sometimes the ways in which issues can look entirely straightforward from afar in fact conceal tremendous complexities on the ground. Certainly profits on particular products, such as they are, must be understood within the context of the larger field. STEM journal publishing is not the same as HSS journal publishing, and they do not strain library budgets in the same ways (Brienza 2012). Monograph and book publishing is not the same as journal publishing, and when one publisher does both the latter typically cross-subsidizes the former (Thompson 2005). Some non-profit university presses may be run like the slickest of businesses, while privately-owned publishing houses might as well be philanthropic enterprises (Haynes 2010). Journal subscription receipts fund scholarly societies which advance and support their respective academic professions (British Sociological Association 2013). And that is just the beginning. Anybody who would tar the entirety of academic publishing with the same brush has not even the most superficial understanding of how academic publishing works.

\section{What Publishers Know Best}

Yet in spite of all of this, the open access activist might still feel within rights to ask sceptically, And so what? Why does it matter that not all academic publishers or academic publishing is the same? It doesn't matter how much you do or don't know about the system; it doesn't matter whether or not publishing professionals are nice people. All you need to know is that the system is broken and in desperate need of fixing. Open Access Now! Well, it matters quite a lot, I would contend, because publishers know better than anyone how publishing actually works and - this is key - how much publishing really costs. If you want to radically transform the funding, production, and distribution models for academic scholarship, who better to consult for advice and insight into making all that work over the long haul than publishers? It is undeniable that, historically, it has been publishers, not academics, who have had to directly grapple with the implementation of new technologies, the withdrawal of public funding for publishing, the competition from international and corporate actors, and all of the other myriad economic, social, and political forces impacting the publishing of scholarship since Cambridge University Press, the oldest university press in the world, printed its first book in 1584 .

Let's consider what I mean in more detail. What do publishers already know that would be worth it for us to learn? In this section, I will focus on two key examples. These are intended merely to be representative, not exhaustive. The first thing that publishers know best is how to survive - if not always thrive precisely as they would wish - in a climate of chronic underfunding. It's all fine and good for academics to call for increased public and philanthropic support for the open dissemination of scholarly production (e.g. Fitzpatrick 2011), but any publisher would know that to see increased charitable giving and/or taxpayer support as a viable alternative to existing revenue models is hopelessly naïve. For instance, where once the publishing activities of university presses were subsidized by their university affiliates, increasingly they are being asked to remit profits back to cash-strapped universities. They have therefore expanded rapidly into other fields, such as trade publishing, textbook publishing, and scholarly journal publishing, which can have higher rates of return, to supplement their "core" monograph publishing business. Other presses, particularly the commercial academic presses in Britain, responded to declining sales caused by shrinking library budgets not just by expanding into other adjacent fields but also vastly increasing their output of monographs and edited collections. Their rationale: If each title sells less, then why not publish more titles? Besides arduously building up, and benefiting from, economies of scale, this, it must be noted, had the salubrious side effect of supporting the careers of scholars working in "new" disciplines such as cultural studies and media studies (recent excoriations of commercial academic presses by scholars in these fields are stupendously ignorant of the symbiotic 
history between disciplinary formations and publishing houses in the twentieth century). Indeed, had publishers relied solely upon public funding, it's likely that the entire academic system, which depends upon the credentialing of peer-reviewed publishing for employment, tenure, and promotion, would have collapsed long ago.

Secondly, publishers know best how to add value to the publishing product, where value needs to be added and how much it will cost, and how to do so in the most cost-effective way. Naturally, publishing history is littered with failed experiments; while they might outsource their editorial and production divisions to India or the Philippines, publishers learned decades ago that eliminating those functions from the value chain altogether met with disastrous consequences. Academics who think they can do it all by themselves, without a crystalclear sense of what "it" entails, seem destined to repeat those failures. Moreover, as digital modes of academic publishing and distribution increase in prominence and complexity, publishers have responded by creatively expanding their role in the slicing, repackaging, and bundling of content, rebranding themselves not merely as book or journal publishers but as information providers and intellectual property managers with a global reach. Because funding is ever-scarce, economies of scale are once again absolutely crucial; it's no coincidence that Elsevier's online "At a glance" profile characterizes itself as "a global company employing more than 7,000 people in 24 countries", "partner[ed] with a global community of 7,000 journal editors, 70,000 editorial board members, 300,000 reviewers and 600,000 authors" ("At a Glance" 2013). Indeed, in two small paragraphs totalling only 149 words, both "global" and "world" appear three times, and "worldwide" appears once.

The "global" orientation of academic publishers producing material in the de facto global language, English, is especially important to bear in mind because many open access initiatives, both top-down government policies and bottom-up grassroots movements, are overly parochial and nationally-oriented. In the United Kingdom, for example, in the wake of the 2012 Finch Report, Research Councils UK has mandated that from April 1, 2013 forward, all scholarly research funded by the Research Councils must be published in open access format. Science and universities minister David Willetts (2013) justifies the move this way: "Every year, the government spends almost $£ 5 b n$ on science and research. Yet the results of that research are generally behind paywalls that individuals and small companies cannot afford, even though they have paid for the research through their taxes". Although he acknowledges that the transition to open access will have upfront costs as funding models are shifted, these "will be partly met by the research councils and also institutions, which should gradually see their library costs reduce in return" (Willetts 2013). It sounds all well and good ... until we bother to remember what publishers already know: the economy for scholarly knowledge is global.

Note how Alicia Wise, Elsevier's Director for Universal Access, speaking before the Business, Innovation, and Skills Committee of the UK House of Commons in April 2013, hedges when asked whether or not the total cost to universities for published research will go up or down. Her reply is as follows: "No, the total cost of the system does not change depending on whether you have the point of payment on the author's side or the reader's side. The total costs of the system are the same but, as you see the majority of content published through open-access fees, you would see a counter-balancing decrease in subscription prices" (quoted in Allington 2013). Parliament is presumably concerned about costs to universities within the UK, but if you believe Elsevier's "At a glance," you will know that the "total system" is not within the UK but rather worldwide. The fact of the matter is that universities in the United Kingdom, while "consistently 'punching above their weight' in global league tables of citations and publications" (Spittle 2013), to use the local argot, represent too small a proportion of global scholarly knowledge production and consumption to move the market in the way that Willetts would suggest. And in fact, the single largest producer and consumer of English-language scholarship, the United States, has a system of higher education so organizationally and economically fragmented that a single open access publishing regime would be virtually impossible to implement either top-down or bottom-up there. In other words, UK open access initiatives as currently formulated will undoubtedly lead to a massive increase in total publishing costs for the UK. Instead of paying twice, once to fund the research and 
again to pay subscription fees to access that research, the public will find itself, in effect, paying thrice - once to fund the research, once to fund open access global publication and dissemination of the results of the research, and a third and final time to pay subscription fees to access critical research conducted throughout the rest of the world which does not operate under the same funding regime.

\section{Collaboration, Not Competition}

So why didn't Wise explain the finer points of the global economy of academic publishing to Parliament? Why wasn't she being completely honest about what she must have already known all too well? If my own informal interactions with publishing professionals are any indication, the reason why she did not is simple: she, along with her employer, is afraid of popular backlash from academics who believe (or have been led to believe by moralizing open access advocates), without truly understanding how much publishing costs or how to pay for it, that publishers are behaving immorally. We are their most important customers, and we hurt them if we withdraw our support.

The open access advocates know this already, of course. But what they have been much slower to realize is that there is a lot to be learned from their counterparts in the industry. Indeed, if academics hope to increase access to the products of scholarship and - far more important - to widen participation in the processes of knowledge production, they would be well-advised to collaborate closely with publishers. As I pointed out above, calls to obsolesce publishers out of existence through public funding and the radical transformation of institutions are hopelessly naïve and arise out of a wilful ignorance of what publishers have already known for a long time. And let's face it, neoliberal market forces upon all aspects of cultural production, academic or otherwise, will not ease just because scholarship has gone "green" (or "gold," or whatever other colour of open access is fashionable at the moment). Funding bodies are unlikely to look favourably upon grant applications supporting open access, say, if the grant writers have no idea how much some successful model of publishing actually costs in the context of, to use Elsevier's technocratic phrase, the "total system". So, like it or not, it's high time, in my view, to treat publishers as collaborators, not competitors.

Indeed, we treat them as competitors at our own risk, for there are few people more anxious about the future than professionals who have been told their industry is dying for the past hundred years or so. As we try to hurt them, they may try to hurt us. And how would they do it? Well, publishers are the first great providers of mass-mediated content; what if they were to develop their own MOOCs, which are, let's face it, really just glorified multimedia textbooks, and found institutions of further and higher learning of their own, while further casualizing, if not completely cutting out, the professoriate altogether? Do you think I'm just fear-mongering? Google "Pearson College" before you jump to any overhasty conclusions. $\mathrm{No}$, it is far better to collaborate with publishers, not to treat them as competition. To do the latter is to risk mutually-assured destruction, and it is only under the influence of the deepest, darkest ignorance and fear that two groups of people so in love with the world of ideas would start those sorts of battles in the first place.

\section{References}

Allington, Daniel. 2013. On Open Access, and Why It's Not the Answer. http://www.danielallington.net/2013/10/open-access-why-not-answer/.

At a Glance. 2013. Elsevier. Accessed November 10. http://www.elsevier.com/about/at-a-glance.

Brienza, Casey. 2012. Opening the Wrong Gate? The Academic Spring and Scholarly Publishing in the Humanities and Social Sciences. Publishing Research Quarterly 28 (3): 159-171. doi:10.1007/s12109-012-9272-5.

British Sociological Association. 2013. An Open and Shut Case, or Merely a Gold Meddle? Network 113: 26-31.

Fitzpatrick, Kathleen. 2011. Planned Obsolescence: Publishing, Technology, and the Future of the Academy. New York: NYU Press.

Haynes, Anthony. 2010. Writing Successful Academic Books. Cambridge: Cambridge University Press. 
Nayyar, Bobby. 2013. Output, Prices, and Social Responsibility. BookBrunch, November 7, 2013. http://www.bookbrunch.co.uk/article_free.asp?pid=output_prices_and_social_responsibility.

Spittle, Graham. 2013. Enabling Innovation to Flourish. University Alliance. Accessed November 10, 2013. http://www.unialliance.ac.uk/campaigns/growingthefuture/innovation/enabling-innovation-toflourish/.

Thompson, John B. 2005. Books in the Digital Age: The Transformation of Academic and Higher Education Publishing in Britain and the United States. Cambridge: Polity Press.

Willetts, David. 2013. We Cannot Afford to Keep Research Results Locked Away in Ivory Towers. The Guardian, April 9, 2013. http://www.theguardian.com/science/political-science/2013/apr/09/openaccess-scientific-publishing-peer-review-scientific-publishing.

\section{About the Author}

\section{Casey Brienza}

is a sociologist and Lecturer in Publishing and Digital Media at City University London's Department of Culture \& Creative Industries. She holds a first degree from Mount Holyoke College, an MA in Media, Culture, and Communication from New York University, and a PhD in Sociology from the University of Cambridge. Her doctoral thesis, titled 'Domesticating Manga: Japanese Comics, American Publishing, and the Transnational Production of Culture,' is currently being revised into a book manuscript. Casey also has refereed articles in print or forthcoming in International Journal of Cultural Policy, Journal of Popular Culture, Studies in Comics, Publishing Research Quarterly, Journal of Graphic Novels and Comics, Logos, and International Journal of the Book. She may be reached through her website http://caseybrienza.com/. 